\title{
Using phenomenography to inform curriculum development in the areas of Digital Curation and Digital Sustainability
}

\section{Tony Reeves}

University for the Creative Arts, Surrey, UK

\section{Abstract}

A British university is proposing to introduce two new postgraduate certificate qualifications in Digital Curation and Digital Sustainability. The proposed courses are intended to formalise this knowledge into a curriculum that enables professional practitioners working in related areas to develop their knowledge of how to manage digital assets in a sustainable manner. This case study sought to investigate the knowledge and skills required by digital professionals working in the areas of Digital Curation and Digital Sustainability at the university. The roles and responsibilities of these professionals were diverse, and the sample included specialists in the areas of digitisation and preservation of archive film and photography, copyright for digital assets, database and web development, bid writing, and managing digitisation projects. A phenomenographic methodology was used to identify the variations in how these professionals understood their work, and the categories of description emerging from the study identified them as researchers, specialist advisors, technical specialists, service providers, and perpetual students. The data analysis and resulting outcome space suggested that a problem-based learning curriculum would provide an effective way of preparing students to succeed as professionals in the areas of Digital Curation and Digital Sustainability.

Keywords: phenomenography; professional practice; curriculum development; problembased learning; digital sustainability. 


\section{Introduction}

The concept and practice of Digital Curation has evolved in response to the need for organisations and individuals to be able to store and retrieve digital assets such as web pages, images, documents and videos (Pennock, 2007; Yakel, 2007). New technologies make it possible for organisations and managers to access the tacit knowledge residing in their employees and groups (Cook and Brown, 1999), but the need for employees to use these technologies effectively has given rise to a corresponding increase in the demand for knowledge management skills (Jarche, 2010; Hart, 2013). By making it possible for employees to 'curate' and access tacit knowledge, digital curation tools can be used to shape the identity and performance of an organisation. The rapid growth in the range of tools used to create and curate digital assets has also brought about a subsequent need to understand how these assets should be managed in the longer term, evidenced through the small but growing body of research in the area of Digital Sustainability (Bradley, 2007; Maron et al., 2009).

Understanding the different roles of knowledge and knowing within organisations is increasingly viewed as a core competency (Cook and Brown, 1999), and some universities have responded to this need to prepare their graduates by either implementing programmes of digital literacy or by embedding the teaching of these literacies into existing curricula (Duggan, 2013). The university in question is seeking to target employees working in relevant professions by providing courses that will enable them to develop their professional practice through better management of digital assets. This research paper used a phenomenographic methodology to investigate the work of digital professionals working in learning support roles at the university in the areas of Digital Curation and Digital Sustainability. The purpose was to analyse the variation in the way that these practitioners understood their work and identify a way to develop a suitable curriculum for future students in these areas. The findings suggested that a problem-based learning curriculum would provide appropriate opportunities for students to acquire the skills and knowledge needed to solve the complex problems that constitute a core aspect of the professional practice of Digital Curation and Digital Sustainability. 


\section{Literature review}

Writing in 1987, the author Donald Schon described what he termed a 'crisis in professional education' (Schon, 1987, p.8), due largely to the perception that 'what aspiring practitioners need most to learn, professional schools seem least able to teach' (Schon, 1987, p.8). This problem is understood as being a symptom of the technicalrational approach to professional education in which the latter is viewed predominantly as the application of technical or specialist knowledge (Cheetham and Chivers, 2000), and numerous subsequent studies have questioned whether this traditional approach produces knowledge which accurately reflects human activities (Bennner, 1984; Dreyfus and Dreyfus, 1986; Giorgi, 1990; Dall'Alba and Sandberg, 1996). Schon (1987) argues that the de-contextualised, research-informed knowledge acquired in such an approach does not reflect the context-specific problems encountered in the 'real' world beyond the classroom, and that in reality practitioners adopt a more reflective approach. However, subsequent research by Cheetham and Chivers (2000) intended to test Schon's hypothesis and revealed that practitioners regularly drew on a combination of both epistemologies, with decision-making reliant on a mixture of intuition, specialist and tacit knowledge (Hatsopoulos and Hatsopoulos, 2009). This suggests that neither the technical-rational epistemology, nor that of the 'knowing-in-action' of Schon's reflective practitioner, explain conclusively the reality of professional practice.

If the aim of a professional practice programme is to prepare students to function effectively within a given profession, accessing and understanding this tacit knowledge can help educators design suitable learning activities to help students acquire relevant expertise (Sternberg and Horvath, 2009). The 'practice' of a profession has been likened to an objective 'container' for the social activity and conventions which constitute that profession (Lave, 1993, p.22). Such interpretations present the container as separate from its content (McDermott, 1993), and as such the latter can be decontextualised and formalised into a programme of professional education (Dall'Alba and Sandberg, 1996). Once students have internalised this content they will be able to operate effectively within the profession (Dall'Alba and Sandberg, 1996). However, critics of this interpretation argue that 'practitioners cannot meaningfully be separated from their activities and the situations in which they practice' (Dall'Alba and Sandberg, 1996, p.413), and hence there is a need for an alternative interpretation of knowledge and competence to help higher education develop effective professional practice programmes (Barnett, 1994). 
The implication that complex, real-world problems are best solved by someone who is able to draw on both specialist knowledge and wealth of experience therefore presents a challenge for professional development curricula: how can 'experience' be taught? To address this problem, Lave (1996) examines the fundamental concepts of teaching and learning and challenges the assumption that the former must be present for the latter to occur. Arguing against the accepted belief that the de-contextualised, classroom model of learning is in some way better than other models, such as apprenticeships, Lave and Wenger (1991) propose that learning should be reconceptualised as a 'situated' activity. Investigating the way in which apprentice tailors learned their craft, Lave concludes that 'the subjects and the world within which they were engaged mutually constituted each other' (Lave, 1996, p.157), implying that learning cannot be divorced from the context in which it occurs. Taking the position that humans shape their identity through social encounters, Lave reasons that as humans learn they are participating in social practice. From this perspective, 'who you are' is fundamentally determined by 'what you know', and 'what you know' might be better understood as an ability to do something, rather than as something which is possessed (Lave, 1996, p.157). By focusing predominantly on learning rather than teaching, Lave proposes that experience can be learned through contextualised, situated activity.

Prior to the work of Lave, Wenger, and Schon, educators at the medical school of McMaster University had faced the challenge of how to provide opportunities for medical students to work on the sort of complex problems they would encounter as professionals. In the 1960s the idea of problem-based learning was developed at McMaster University Medical School (Savin-Baden and Major, 2004) and has subsequently been adopted in disciplines including Economics, Law and Business Administration (Barrows, 1996). Problem-based learning requires students to work collaboratively in small groups to discuss and solve meaningful problems (Schmidt, 1983). Loyens et al. (2008) highlight that a key element of problem-based learning is that students discuss the problem before they have received other curriculum inputs. Based on their initial discussion, students then identify what it required in terms of their own self-directed learning before their next meeting where they share and critically evaluate their findings (Schmidt, 1983). The role of the tutor in this process is to facilitate the discussion, provide additional, relevant context where necessary, and monitor the contribution of each group member. Problem-based learning can therefore be seen as helping students to learn through contextualised activity rather than through teaching (Lave, 1996). 


\section{Research question}

This case study aimed to investigate the roles and responsibilities of professionals working in the areas of Digital Curation and Sustainability. The following research question formed the basis of the research:

- What knowledge and skills would students on courses in Digital Curation and Digital Sustainability need to acquire to become successful practitioners in the field?

\section{Methodology}

As this research focused on a specific example of the practice of digital professionals, a case study approach was used as it would allow the situated nature of their work to be taken into account (Cohen et al., 2007). Although the qualitative nature of a case study has led to it being traditionally considered as a 'soft' form of research when compared with 'hard', quantitative methods (Yin, 2009), statistical and numerical approaches do not often permit as thorough an exploration of a given situation as a case study (Cohen et al., 2007). A qualitative approach also permits the researcher to arrive at an understanding of a situation from the perspective of those experiencing it - the 'emic' or insider's perspective - rather than from the outsider's 'etic' perspective of the researcher (Hancock and Algozzine, 2011). As the aim of this research was to understand the nature of the work undertaken by the practitioners, rather than to test a pre-existing hypothesis, it was felt that a descriptive case study using narrative accounts would enable a comprehensive understanding of their professional roles (Yin, 1984; Merriam, 1988).

\section{Methodology and data collection}

A phenomenographic methodology using semi-structured interviews was used to gather and analyse the data. Phenomenography is a qualitative methodology developed by Ference Marton $(1981 ; 1986)$ which permits a researcher to study the variation in how people understand or experience a phenomenon (Larsson and Holmstrom, 2007). Such an approach aims to identify the variations in descriptions of the phenomenon under investigation (Marton and Booth, 1997), enabling the researcher to understand the different ways in which individuals interpret their reality (Marton, 1986). These variations 
are named 'categories of description' and their subsequent comparison permits the construction of an 'outcome space', the purpose of which is to illustrate the non-dominant ways of understanding the phenomenon under investigation. This is achieved by seeking statements made by interviewees which describe different ways of understanding the phenomenon (Larsson et al., 2010). The subsequent outcome space therefore represents the full extent of this understanding in which no single interpretation dominates another.

There are several variations on the 'classic' phenomenographic methodology as proposed by Marton (1986; 1994). The current study followed the seven stage variation used by Larsson and Holmstrom (2007) to investigate the professional work of anaestheologists. Once interview data has been collected and transcribed, this process involves:

1) Reading each transcription;

2) Re-reading the transcriptions, then marking up the passages of text where an interviewee has provided a direct response to a key question;

3) Identifying in these passages the focus of the interviewee's attention, then writing a short summary of how the interviewee describes their work;

4) Grouping these descriptions into categories to form categories of description;

5) Establishing non-dominant ways of understanding the categories;

6) Constructing an outcome space to reflect the hierarchical relationship between the categories;

7) Formulating a metaphor for each group of categories.

In the final step, a metaphor is assigned to each group of categories in order to improve understanding of the data analysis (Miles and Huberman, 1984). This practice is a method of displaying in data in qualitative analysis that can be understood as 'using one object to create a new perspective on another' (Smith, 1988, p.4) to aid comprehension.

For the current study, purposive sampling was used to identify six practitioners with suitable knowledge and experience of Digital Curation and Digital Sustainability. The professional work of these practitioners was known to the researcher through previous collaborations and projects, and this knowledge was considered a suitable basis for asking them to participate in the study. Their work was often project-based and included the digitisation and preservation of special collections such as dresses and films, advising the university on copyright risk for digital assets, developing image databases and websites, 
writing bids for digitisation projects, and developing and managing the institutional repository of staff research outputs.

A project information sheet explaining the rationale and scope of the research was given to each practitioner to enable them to make an informed decision as to whether they wished to participate. All six practitioners agreed to be interviewed, and semi-structured interviews were then used to elicit responses regarding their professional work. During these interviews, participants were asked the three questions used by Larsson and Holmstrom (2007) in their investigation into the professional practice of anaestheologists to discover how they experienced their work. These questions were themselves derived from previous phenomenographic studies into how undergraduate students experience medical practice (Dall'Alba, 1998) and the experience of healthcare professionals caring for patients with diabetes (Holmstrom et al., 2003). The open-ended questions aim to provide interviewees with sufficient opportunities to reflect on and describe their experiences of the phenomenon under investigation:

1. What is the core of your professional work?

2. When do you feel you have been successful in your work?

3. What is difficult or what hinders you in your work?

Interviews were recorded using a Zoom HD digital recorder and were transcribed verbatim, making the transcripts the focus of the data analysis (Akerlind, 2012). Creating transcripts of all six interviews enabled the researcher to become familiar with the data through repeated readings in order to permit the emergence of categories of description.

\section{Researcher bias and reliability}

In qualitative studies there is an inevitable risk that the researcher's prior knowledge could influence the collection and analysis of data (Cohen et al., 2007). In phenomenographic research, the researcher is advised to 'bracket' this prior knowledge by striving to remain conscious of their own thoughts and preconceived ideas (Crabtree and Miller, 1999). In the present study, the researcher consciously identified his personal views and held them in mind during both the data collection and analysis so as to minimise their influence and permit the emergence of authentic categories of description. 
To achieve reliability in phenomenographic research it is also desirable that the data is analysed by a second researcher, thus allowing an independent interpretation which can be compared against the primary researcher's findings (Larsson and Holmstrom, 2007). However, the time constraints of the current study meant that it was not possible for a second analysis to be conducted.

\section{Ethical issues}

The research proposal was reviewed by a senior member of the Educational Research department and, as it was deemed to present minimal ethical risk to the participants, it was not submitted to the University Ethics Committee. However, a potential issue was identified regarding interviewee confidentiality, for although interviewees were assured that their identities would not be revealed in the research, the use of face-to-face interviews meant that it was not possible to guarantee the anonymity of responses (Cohen et al., 2007). By describing the work of specialist teams at the university it was also possible that their identities could be inferred through the research. The interviewees were informed of this risk both orally and by way of a project information sheet, and were offered the right to withdraw from the study at any time. Interviewees signed a consent form to provide written consent for their participation in the research. Although the researcher knew the interviewees and had worked alongside them in previous projects, it was not felt that this would significantly alter the way in which they understood and described their professional work.

\section{Data analysis and findings}

In Table 1 below, column 1 provides examples of the foci that emerged from the analysis of each transcript. Column 2 indicates how interviewees described their professional activities in each area. 
Table 1. Examples of the foci of interviewees' activity and descriptions of their work.

\begin{tabular}{|l|l|}
\hline Focus & Description \\
\hline $\begin{array}{l}\text { Researching digital } \\
\text { artifacts }\end{array}$ & $\begin{array}{l}\text { Developing and conducting research projects e.g. doing } \\
\text { interviews, surveys, creating research outputs. } \\
\text { Understanding how digital artifacts are used in teaching and } \\
\text { learning. }\end{array}$ \\
\hline $\begin{array}{l}\text { Managing research } \\
\text { projects }\end{array}$ & Writing, following and updating project plans. \\
\hline $\begin{array}{l}\text { Disseminating new } \\
\text { knowledge }\end{array}$ & $\begin{array}{l}\text { Presenting research findings at conferences, workshops and in } \\
\text { journals. } \\
\text { Participating in communities of practice. }\end{array}$ \\
\hline Providing online systems & $\begin{array}{l}\text { Providing, developing and maintaining online platforms to } \\
\text { enable users to access digital artifacts. }\end{array}$ \\
\hline Strategic direction & \begin{tabular}{l} 
Keeping systems online by backing up and testing backups. \\
Aligning service provision with university strategies to help \\
them achieve their objectives. \\
\hline
\end{tabular} \\
\hline \begin{tabular}{l} 
Articulating the value and risks of digitisation for the university. \\
\hline
\end{tabular}
\end{tabular}

In total thirteen distinct foci emerged from the data analysis, and these descriptions were then grouped into categories. In Larsson and Holmstrom's (2007) example, the researchers apply metaphors to each category of description prior to the attempted construction of the outcome space, and it is these metaphors that in fact make it possible to establish the non-dominant ways of understanding. Following their example, metaphors were assigned to each group of categories and these are presented in Table 2 below:

Table 2. Grouped categories of description and assigned metaphors.

\begin{tabular}{|l|l|}
\hline Grouped categories of description & Metaphor \\
\hline $\begin{array}{l}\text { Researching the use of digital artifacts } \\
\text { Managing research projects } \\
\text { Creating and disseminating new knowledge } \\
\text { Securing research funding }\end{array}$ & A: Digital professional as researcher \\
\hline $\begin{array}{l}\text { Creating digital artifacts } \\
\text { Providing, maintaining and updating online } \\
\text { platforms and interfaces } \\
\text { Managing digital and analogue artifacts }\end{array}$ & B: Digital professional as technical expert \\
\hline
\end{tabular}




\begin{tabular}{|l|l|}
\hline $\begin{array}{l}\text { Providing strategic direction for digitisation } \\
\text { Marketing and monetising service } \\
\text { Evaluating service provision }\end{array}$ & C: Digital professional as service provider \\
\hline $\begin{array}{l}\text { Keeping professional knowledge up to date } \\
\text { Learning on the job } \\
\text { Being multi-skilled }\end{array}$ & D: Digital professional as perpetual student \\
\hline $\begin{array}{l}\text { Providing mentoring and governance } \\
\text { Supporting learning } \\
\text { Writing policies and procedures } \\
\text { Advising on copyright diligence and IPR }\end{array}$ & E: Digital professional as specialist advisor \\
\hline
\end{tabular}

In some phenomenographic studies a short summary of the assigned metaphors is provided to explain how a practitioner operating in each paradigm relates to their work (Dall'Alba and Sandberg, 1996; Dall'Alba, 1998; Sjostrom and Dahlgren, 2002; Larsson and Holmstrom, 2007). A summary of the metaphors in the current study can be found below along with quotations from the transcripts to support the metaphors:

A. Digital professional as researcher: in this paradigm the focus was on research as a core element of professional work. The job of the digital professional was to engage with existing research projects, either through doing research or managing projects. These projects aimed to identify new research questions in the areas of Digital Curation and Digital Sustainability that aligned with the strategic aims of the university. Responsibilities included managing budgets, coordinating external project partners, completing written reports for the funders, and disseminating outputs at national and international conferences and via peer-reviewed journals:

We've got this research remit as well - in that we're not just creating, managing, digital data... but we're also trying to be proactive in actually researching how that's done.

My prime objective is really bid writing, is writing that funding bid that actually secures you the funding to pursue a particular area of research in the field. And then carrying on that piece of work.

B. Digital professional as technical expert: this metaphor highlighted the focus of professional work on the creation and post-production of digital artifacts using an array of specialist equipment and software. This required knowledge of both the equipment and the 
legal implications of digitising artifacts to ensure compliance with current copyright laws. Artifacts needed to be curated and catalogued using relevant metadata and encoding procedures to ensure that they were discoverable by search engines. Storing artifacts required both an ability to work with databases and the skills to design and update interfaces to make the artifacts discoverable and sustainable:

We set out the basic things like file formats, metadata, and all those kind of technical hands-on things, provide policies and guidelines around that. IPR advice and guidance.

We are also in charge of the technical side of the preservation of high resolution images that we've been acquiring over the last thirteen years, and there is a policy that we have to preserve them indefinitely.

C. Digital professional as service provider: this metaphor reflected the 'public-facing' nature of activity, whether internally to students and academics or to external clients paying for services. Those leading the teams were responsible for establishing key performance indicators and measuring progress against them in order to demonstrate demand and impact. This required the teams to implement tools and methods of monitoring and evaluating the usage of their services in order to justify their existence. Increasing usage required the teams to develop physical and online marketing materials to promote their services both within and outside the institution:

You have to market yourself in a way that a commercial business would.

We have this remit or objective that all our databases need to be up and running... so we need to make sure that they are properly backed up and looked after.

D. Digital professional as perpetual student: the need for continual training and development was highlighted as an essential factor in providing an effective service, and reflected the literature emphasising the importance of lifelong learning (Evers et al., 1998; Field, 2006; Blaschke, 2012). Remaining informed of changes to copyright law was a key area of concern, as was the need to monitor how file formats are changing and the implications for sustaining access to digital artifacts. The data also indicated that interviewees often found themselves operating at the boundaries of their professional 
knowledge, in what Schon $(1987$, p.6) describes as 'indeterminate zones of practice'. Completing a given task often involved having to improvise based on accumulated knowledge and experience, resulting in 'learning on the job'.

You've got to be up-to-date really, more than anything else. So from my perspective that's one of the most important things.

I'm always very conscious of keeping up to speed.

E. Digital professional as specialist advisor: providing specialist advice to students, academics and senior management was a regular activity. This advice ranged from the practicalities of using digitisation equipment to ensuring that students and academics understood the implications of digitising their work, and required an understanding of their specific context at the university. Providing specialist advice on both the strategic role of digital services and the need to manage risk copyright took place through the writing of policies, technical specifications and workflows, and through face-to-face meetings with key stakeholders.

If [students and staff] need any help, they want to digitise something and they're not sure how to go about it, what's the correct format, the right procedure? So we'd help advise on that.

We also have a remit to provide a strategic direction for digitisation across the university.

These metaphors were then used to establish the hierarchical relationships between categories, and these are discussed in the following section.

\section{Discussion of findings}

The data indicated that maintaining currency of professional knowledge was fundamental to the activities of all the interviewees, regardless of their specialism, and category $D$ (perpetual student) therefore constitutes the bottom of the hierarchy. Given the rapidly changing nature of knowledge in the digital professions (Choi and Rasmussen, 2006; 
Kennan et al., 2006), it can be assumed that remaining informed of new developments is of growing importance to professionals. Entering the paradigm of the technical expert (B) can only be achieved by maintaining currency of knowledge of new systems, processes and ways of working, and category $B$ is therefore dependent on category $D$. To be a specialist advisor (E) capable of supporting learning and providing strategic guidance, a practitioner needs to be both a technical expert and be at the forefront of new developments in their field. Category $E$ is therefore dependent on categories B and D. Inhabiting the role of the service provider $(\mathrm{C})$ is only possible if a practitioner is able to provide specialist advice $(E)$ based on their specialist technical ability $(B)$ which is informed by current knowledge and thinking (D). Category $C$ is therefore dependent on $E, B$, and $D$ respectively.

Central to the researcher paradigm $(A)$ is the creation and dissemination of new knowledge, and it is this interpretation of research that differentiates it from the more general interpretation of researching existing knowledge that might occur in category $D$ (perpetual student). Writing up and disseminating research can be viewed as providing specialist advice as its purpose is to enable others to change their practice in light of the research, and category $A$ (researcher) is therefore dependent on category $E$ (specialist advisor). If it is not possible to be a specialist advisor without being a technical expert who is informed by current knowledge, then $A$ is also dependent on $B$ (technical expert) and $D$ (perpetual student). Researching often seeks to investigate issues encountered by online service providers in order to identify possible causes and potential solutions and help them improve their service (Wu and Wang, 2005; Jøsang et al., 2007). However, it is still possible to be a service provider without creating new knowledge, and the converse is also true in that it is possible to engage in research and the creation of new knowledge without providing a service. Categories $A$ and $C$ can therefore be seen as being neither dominated by, nor dependent on, each other. The hierarchical relationships between the categories of description are presented in Figure 1 below: 
Figure 1. Outcome space indicating hierarchical relationships between categories.

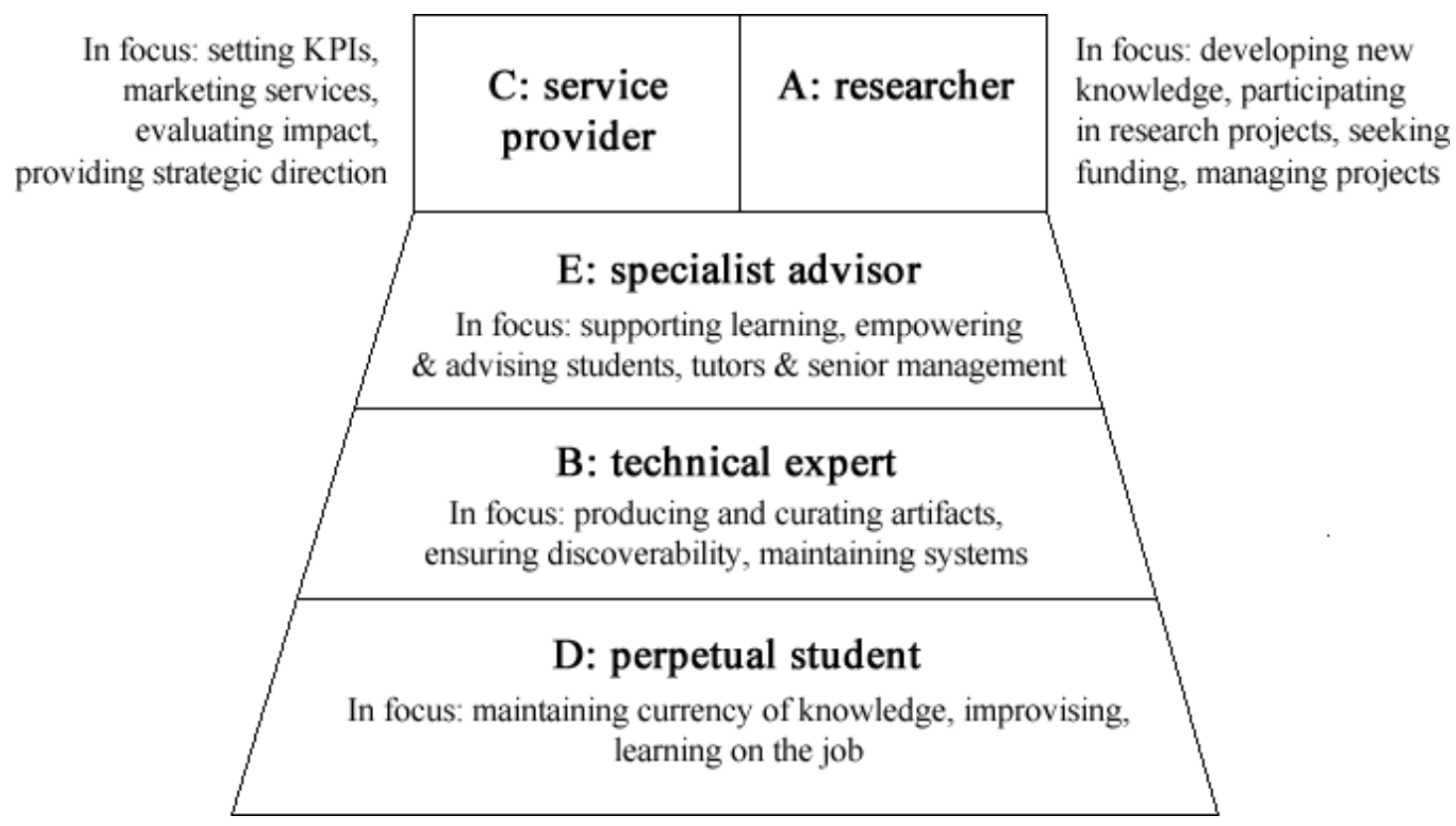

\section{Developing appropriate curricula}

The research revealed that the digital professionals possessed significant tacit knowledge which would be difficult to teach if divorced from its context. This suggests that problembased learning would be a suitable approach to designing appropriate curricula as it would require students to develop knowledge and skills through problem solving (Schmidt, 1983; Loyens et al., 2008). It is likely that the digital professionals who would be teaching on the course would also feel more comfortable with a problem-based curriculum as it would enable them to use their expertise to design problems which would be familiar to them and facilitate student-centred discussion, rather than trying to distil their knowledge and skills into decontextualised lectures and presentations. It is likely that their experience of the many problems that arise during project-based work would enable the digital professionals to develop the ill-structured problems that form the basis of a problem-based learning curriculum (Allen et al., 1996; Gallagher, 1997).

The data revealed that much of the practice of the digital professionals who participated in the study was highly situated. Although participants did attend developmental events to acquire new knowledge, for example around copyright law, they made sense of this new information largely through applying it to real problems and projects within their own institution. If 'what you know' might be better understood as an ability to do something 
(Lave, 1996), then the findings suggest that a course in Digital Curation and Sustainability should aim to assess students based on their ability to solve problems by drawing on their experience. A suitable curriculum would therefore need to provide regular opportunities for students to work on real or simulated problems so that they can acquire the contextspecific knowledge and skills to operate effectively in what Schon $(1987$, p.3) terms the 'swampy lowlands' of professional practice.

Loyens et al. (2008) state that a key aim of a problem-based learning curriculum is to enable students to develop their self-directed learning skills, and highlight Candy's (1991) four dimensions of self-directed learning: personal autonomy, self-management in learning, the independent pursuit of learning, and the learner control of instruction. In view of the finding that identified digital professionals as 'perpetual students', a problem-based learning approach would therefore be appropriate as it would encourage students to develop a strong aptitude for self-directed learning. In describing the complex nature of the projects they often worked on, the participants revealed that an essential aspect of their role was the need to learn new skills to complete a project. Encouraging students to develop a self-directed approach to their learning is therefore a key objective of a curriculum in Digital Curation and Sustainability, as it would aim to make students aware that they often need to act autonomously in order to seek out and acquire the knowledge and skills necessary to solve a problem.

Group work also plays an essential role in problem-based learning, with the instructor facilitating group discussions and teaching students how to work effectively in a group (Bridges and Hallinger, 1996). The data revealed that much of the participants' expertise had been acquired and developed through project-based work, and so providing opportunities for group work in the curriculum would enable students to develop their ability to work collaboratively.

\section{Conclusion}

This research aimed to uncover the skills and competencies that students would need to acquire while undertaking a course in Digital Curation and Digital Sustainability. The categories of description that emerged during the data analysis have uncovered the core of the professional work undertaken by digital professionals at the university and the main 
foci of their activity. The category of the perpetual student and its position as the foundational layer of the outcome space highlights Schon's (1987) position that 'knowingin-action' is central to professional practice, and that much of this knowledge is acquired through situated learning. The observation that the participants were consistently operating in 'zones of indeterminate practice' (Schon, 1987, p.6) supports the view that professionals are more than just people applying specialist knowledge (Cheetham and Chivers, 2000). The outcome space itself indicates the dependency of each specific area of expertise and could be interpreted as representing a form of progression through the disciplines of Digital Curation and Digital Sustainability, although further research is required to confirm this hypothesis.

The findings of this research illustrate the diverse nature of the work undertaken by digital professionals operating in the areas of Digital Curation and Digital Sustainability. Having identified the complex nature of their work, it is proposed that introducing a problem-based learning curriculum would enable students in the areas of Digital Curation and Sustainability to acquire the skills and knowledge required to succeed in these professional areas. Although the findings suggest that much of the knowledge acquired by the digital professionals has occurred through situated learning, there is still a risk that the categories of description could be used to decontextualise this knowledge and package it into a programme of learning that students acquire before entering the 'container' of professional practice (Lave, 1993). Further research would explore the development of suitable problem-based learning activities to facilitate the acquisition of the knowledge and skills identified in the study.

\section{References}

Akerlind, G. (2012) 'Variation and commonality in phenomenographic research methods', Higher Education Research and Development, 31(1), pp. 115-127.

Allen, D.E., Duch, B.J. and Groh, S.E. (1996) 'The power of problem-based learning in teaching introductory science courses', in Wilkerson, L. and Gijselaers, W.H. (eds.) Bringing problem-based learning to higher education: theory and practice. San Francisco: Jossey-Bass, pp. 43-52. 
Barnett, R. (1994) The limits of competence: knowledge, higher education and society. Buckingham: SHRE and Open University Press.

Barrows, H.S. (1996) 'Problem-based learning in medicine and beyond: a brief overview', in Gijselaers, W.H. (ed.) New directions for teaching and learning, no. 68. San Francisco: Jossey-Bass, pp. 3-11.

Benner, P. (1984) From novice to expert: excellence and power in clinical nursing practice. San Francisco: Addison-Wesley.

Blaschke, L.M. (2012) 'Heutagogy and lifelong learning: a review of heutagogical practice and self-determined learning', International Review of Research in Open and Distance Learning, 13(1) [Online]. Available at: http://www.irrodl.org/index.php/irrodl/article/view/1076/2087 (Accessed: 18 November 2014).

Bradley, K. (2007) 'Defining digital sustainability’, Library Trends, 56(1), pp. 148-163.

Bridges, E.M. and Hallinger, P. (1996) 'Problem-based learning in leadership education', in Wilkerson, L. and Gijselaers, W.H. (eds.) Bringing problem-based learning to higher education: theory and practice. San Francisco: Jossey-Bass, pp. 53-61.

Candy, P.C. (1991) Self-direction for lifelong learning. San Francisco: Jossey-Bass.

Cheetham, G. and Chivers, G. (2000) 'A new look at competent professional practice', Journal of European Industrial Training, 27(7), pp. 374-383.

Choi, Y. and Rasmussen, E. (2006) 'What is needed to educate future digital librarians: a study of current practice and staffing patterns in academic and research libraries', D-Lib Magazine, 12(9) [Online]. Available at: http://www.dlib.org/dlib/september06/choi/09choi.html (Accessed: 18 November 2014).

Cohen, L., Manion, L. and Morrison, K. (2007) Research methods in education. Oxon: Routledge. 
Cook, S.D.N. and Brown, J.S. (1999) 'Bridging epistemologies: the generative dance between organizational knowledge and organizational knowing', Organization Science, 10(4), pp. 381-400.

Crabtree, B. and Miller, W. (1999) Doing qualitative research. $2^{\text {nd }}$ edn. London: Sage.

Dall'Alba, G. (1998) 'Medical practice as characterised by beginning medical students', Advances in Health Sciences Education, 3(2), pp. 101-118.

Dall'Alba, G. and Sandberg, J. (1996) 'Educating for competence in professional practice', Instructional Science, 24(6), pp. 411-437.

Dreyfus, H. and Dreyfus, S. (1986) Mind over machine: the power of human intuition and expertise in the era of the computer. New York: Free Press.

Duggan, F. (2013) 'Why universities should acquire - and teach - digital literacy', The Guardian, Blog, 23 April [Online]. Available at:

http://www.theguardian.com/education/2013/apr/23/universities-should-teachdigital-literacy (Accessed: 12 November 2013).

Evers, F., Rush, J. and Berdrow, I. (1998) The bases of competence: skills for lifelong learning and employability. Ontario: Jossey-Bass.

Field, J. (2006) Lifelong learning and the new educational order. London: Trentham Books.

Gallagher, S.A. (1997) 'Problem-based learning: where did it come from, what does it do, and where is it going?', Journal for the Education of the Gifted, 20(4), pp. 332-362.

Giorgi, A. (1990) 'Phenomenology, psychological science and common sense', in Semin, G.R. and Gergen, K.J. (eds.) Everyday understanding: social and scientific implications. London: Sage, pp. 64-82.

Hancock, D. and Algozzine, B. (2011) Doing case study research: a practical guide for beginning researchers. $2^{\text {nd }}$ edn. New York: Teachers College. 
Hart, J. (2013, 25 June) 'From creating content to building new connected workplace skills - this is the NEW work for learning professionals', Learning in the social workplace [Online]. Available at: http://www.c4lpt.co.uk/blog/2013/06/25/connected-workplace/ (Accessed: 12 November 2013).

Hatsopoulos, G. and Hatsopoulos, M. (2009) 'The role of tacit knowledge in management', in Sternberg, R. and Horvath, J. (eds.) Tacit knowledge in professional practice: researcher and practitioner perspectives. London: Lawrence Erlbaum Associates, pp. 141-152.

Holmstrom, I., Halford, C. and Rosenqvist, U. (2003) 'Swedish health care professionals' diverse understandings of diabetes care', Patient Education and Counselling, 5(1), pp. 53-58.

Jarche, H. (2010, October 22). Network learning: working smarter. Life in perpetual beta [Online]. Available at: http://www.jarche.com/2010/10/network-learning-workingsmarter/ (Accessed: 12 November 2013).

Jøsang, A., Ismail, R. and Boyd, C. (2007) 'A survey of trust and reputation systems for online service provision', Decision Support Systems, 43(2), pp. 618-644.

Kennan, M.A., Willard, P. and Wilson, C.S. (2006) 'What do they want? A study of changing employer expectations of information professionals', Australian Academic and Research Libraries, 37(1), pp. 17-37.

Larsson, J. and Holmstrom, I. (2007) 'Phenomenographic or phenomenological analysis: does it matter? Examples from a study on aneastheologists' work', International Journal of Qualitative Studies on Health and Well-Being, 2(1), pp. 55-64.

Larsson, I., Bergman, S., Fridlund, B. and Arvidsson, B. (2010) 'Patients' independence of a nurse for the administration of subcutaneous anti-TNF therapy: a phenomenographic study', International Journal of Qualitative Studies on Health and Well-being, 5(2), pp. 5146-5155. 
Lave, J. (1993) 'The practice of learning', in Chaikin, S. and Lave, J. (eds.) Understanding practice: perspectives on activity and context. Cambridge: Cambridge University Press, pp. 3-32.

Lave, J. (1996) 'Teaching, as learning, in practice', Mind, Culture, and Activity, 3(3), pp. 149-164.

Lave, J. and Wenger, E. (1991) Situated learning: legitimate peripheral participation. New York: Cambridge University Press.

Loyens, S.M., Magda, J. and Rikers, R.M. (2008) 'Self-directed learning in problem-based learning and its relationships with self-regulated learning', Educational Psychology Review, 20(4), pp. 411-427.

Maron, N., Kirby Smith, K. and Loy, M. (2009) Sustaining digital resources: an on-theground view of projects today. London: JISC.

Marton, F. (1981) 'Phenomenography - describing conceptions of the world around us', Instructional Science, 10(2), pp. 177-200.

Marton, F. (1986) 'Phenomenography - a research approach investigating different understandings of reality', Journal of Thought, 21(2), pp. 28-49.

Marton, F. (1994) 'Phenomenography', in Husen, T. and Postlethwaite, T.N. (eds.) The international encyclopedia of education. $2^{\text {nd }}$ edn. Vol. 8. Oxford: Pergamon, pp. 4424-4429.

Marton, F. and Booth, S. (1997) Learning and awareness. Hillsdale, NJ: Lawrence Eribaum.

McDermott, R. (1993) 'The acquisition of a child by a learning disability', in Chaikin, S. and Lave, J. (eds.) Understanding practice: perspectives on activity and context. Cambridge: Cambridge University Press, pp. 269-305.

Merriam, S. (1988) Case study research in education. San Francisco, C.A: Jossey Bass. 
Miles, M. and Huberman, A. (1984) Qualitative data analysis: a sourcebook of new methods. Newbury Park: CA: Sage.

Pennock, M. (2007) 'Digital curation: a life-cycle approach to managing and preserving usable digital information', Library and Archives Journal, 1 [Online]. Available at: http://www.ukoln.ac.uk/ukoln/staff/m.pennock/publications/docs/libarch curation.pdf (Accessed: 18 November 2014).

Savin-Baden, M. and Major, C.H. (2004) Foundations of problem-based learning. Berkshire: SRHE and Open University Press.

Schmidt, H.G. (1983) 'Problem-based learning: rationale and description', Medical Education, 17(1), pp. 11-16.

Schon, D.A. (1987) 'Preparing professionals for the demands of practice', in Schon, D.A. (ed.) Educating the reflective practitioner. San Francisco: Jossey-Bass, pp. 3-21.

Sjostrom, B. and Dahlgren, L.O. (2002) 'Applying phenomenography in nursing research', Journal of Advanced Nursing, 40(3), pp. 339-345.

Smith, N. (1988) 'Mining metaphors for methods of practice', in Fetterman, D.M. (ed.) Qualitative approaches to evaluation education: the silent scientific revolution. New York: Praeger, pp. 153-175.

Sternberg, R.J. and Horvath, J.A. (eds.) (2009) Tacit knowledge in professional practice: researcher and practitioner perspectives. London: Lawrence Erlbaum Associates.

Wu, J.-H. and Wang, S.-C. (2005) 'What drives mobile commerce? An empirical evaluation of the revised technology acceptance model', Information and Management, 42(5), pp. 719-729.

Yakel, E. (2007) ‘Digital curation’, OCLC Systems and Services, 23(4), pp. 335-340.

Yin, R. (1984) Case study research: design and methods. Beverley Hills: Sage. 
Yin, R. (2009) Case study research: design and methods. $4^{\text {th }}$ edn. London: Sage.

\section{Author details}

Tony Reeves is a Programme Manager in Digital Pedagogy in the Centre for Digital Scholarship at the University for the Creative Arts. Currently a doctoral student in Technology Enhanced Learning at the University of Lancaster, his research focuses on the impact of online communities on student learning in higher education. 